\title{
The Pursuit of Organizational Well-Being-an Exploratory Study in a Public Research Agency
}

\author{
Elisa Colì and Antonella Rissotto
}

\begin{abstract}
The aim of this paper is to identify the key areas that contribute to organizational well-being in the Italian National Research Council (CNR), the major Public Research Agency in Italy. Through this study we want to contribute to the definition of this construct in specific contexts, such as research agencies and universities. 7 focus groups were carried out involving 61 employees with different professional roles and profiles. Using qualitative data analysis software NVivo9, we identified 6 key areas of organizational well-being in the CNR. The results of this study highlight the value not only of human resources management, but also of knowledge management, relationships, clarity of the Agency vision and employee future outlook, motivation and participation in decision making as important factors for organizational well-being of a research agency. We propose interventions for organizational health promotion, aimed at creating a learning organization and at activating knowledge management processes.
\end{abstract}

Index Terms-Dimensions of organizational well-being, evaluation and promotion of organizational well-being, exploratory study, Research Agency.

\section{INTRODUCTION}

Occupational psychology's interest in the topic of organizational well-being has been growing [1]-[2] and the issue has become the subject of several research studies. The literature has shown that feeling good at work has benefits for both the person and the organization; for the former, because it contributes to the state of physical and psychological well-being, and for the latter, because it increases efficiency and productivity [3]-[4].

Some studies investigated specific aspects, such as the impact of the organizational climate on organizational health [5], whereas recent research has emphasized the link between job performance, psychological well-being and organizational commitment [6]. Other studies have validated multidimensional models in which the construct of psychological well-being has been integrated with the construct of organizational well-being. For example van Horn, Schaufeli \& Schreurs [1], starting from the conceptualization of well-being suggested by Warr [7] and Ryff \& Keyes [8], developed a five-dimensional model of well-being where the dimensions were affective, professional, social, cognitive and psychosomatic. Wilson, Dejoy, Vandenberg, Richardson \& McGrath [9], instead, conceptualized and started to test a healthy work organization

Manuscript received December 20, 2012; revised January 21, 2013.

The authors are with the Institute of Cognitive Sciences and Technologies - Italian National Research Council, Rome, 00185 ITALY (e-mail: elisa.coli@istc.cnr.it, antonella.rissotto@istc.cnr.it). model.

Organizational well-being is a complex, multidimensional [7]-[10] and dynamic construct. It consists of several interdependent levels and is context influenced. These characteristics have made a shared conceptualization of the construct and the construction of survey instruments difficult. Recent research in this field aimed to develop assessment tools suited to specific categories of workers, such as police officers [11], or to specific contexts, such as schools [12].

The lack of studies on organizational well-being developed for research agencies and universities should be pointed out. In Italy, between 2003 and 2013, 300 public administrations evaluated their organizational well-being within the Magellano project, sponsored by the Department of Public Administration. However, only $4.67 \%$ of the public administrations were universities and $1.33 \%$ were research agencies [13]. Nevertheless, the number of Italian research agencies that, following legislative directives (e.g. legislative decree n. 150/2009 [14]), have been conducting exploratory and experimental investigations on organizational well-being, is increasing. These studies have been performed both by using research tools validated in other contexts, such as the Multidimensional Organizational Health Questionnaire [15], and by developing original assessment instruments. One of these agencies is the Italian National Research Council, the largest Public Research Agency in Italy, which in 2011 started the project "Survey on organizational well-being in the CNR" [16]. The aim of the project was to develop a questionnaire for the evaluation of organizational well-being able to take into account the specificity of the CNR context and at the same time suited to other similar organizations. This exploratory study represented the first step in developing this instrument.

\section{CONTEXT}

The study was performed in the CNR, whose mission is to produce value through research knowledge [17]. The CNR is present over the national territory through a network of 107 research Institutes [18]. 7996 employees work within the Agency, $60 \%$ of whom are researchers and $40 \%$ of whom are administrative and technical staff. 2971 are external members, who collaborate with the CNR or train at the Agency. $41 \%$ of the externals are associate professors and 59\% are postgraduate researchers [19]. Therefore, from an organizational point of view it is possible to identify essentially two "cultural souls" within the organization: the central administration and the research network. 


\section{RESEARCH QUESTION}

The main aim of this study is to identify the areas and the dimensions of organizational well-being in the CNR, to contribute to the definition of the construct in specific contexts, such as research agencies and universities.

\section{Methodology}

Qualitative research tools were selected to emphasize meanings and processes, rather than measurements and cause-effect relationships, which can be better understood by quantitative research tools. In particular, focus groups were carried out involving 61 employees with different professional roles and profiles in the CNR. The main aim of the focus groups was to explore the experiences and feelings of CNR employees and to identify factors that promote or hinder organizational well-being in the Agency.

Overall, as shown in Table I, 7 focus groups were held: 2 with managers of the central administration (19 people), 1 with directors of the research Institutes ( 8 people), 2 with administrative/technical employees working in the central administration (18 people) and finally 2 with researchers working in the research Institutes located in different geographical areas (16 people). The survey sample was put together taking into account both the professional profiles of employees and the two "cultural souls" of the Agency. In the case of the research Institutes, we take into account also the geographical location.

TABLE I: FOCUS GROUPS AND COMPOSITION

\begin{tabular}{|c|c|c|c|}
\hline $\begin{array}{l}\mathrm{N}^{\circ} \\
\text { focus } \\
\text { groups }\end{array}$ & $\begin{array}{l}\mathrm{N}^{\circ} \\
\text { participants }\end{array}$ & Profile & Unit of affiliation \\
\hline 2 & 19 & Managers & $\begin{array}{l}\text { Central } \\
\text { administration }\end{array}$ \\
\hline 1 & 8 & Directors & $\begin{array}{l}\text { Research } \\
\text { Institutes }\end{array}$ \\
\hline 2 & 18 & $\begin{array}{l}\text { Administrative/technical } \\
\text { profiles }\end{array}$ & $\begin{array}{l}\text { Central } \\
\text { administration }\end{array}$ \\
\hline 2 & 16 & Researchers & $\begin{array}{l}\text { Research } \\
\text { Institutes }\end{array}$ \\
\hline \multicolumn{4}{|l|}{ Total } \\
\hline 7 & 61 & & \\
\hline \multicolumn{4}{|c|}{ TABLE II: GENDER OF FOCUS GROUP PARTICIPANTS } \\
\hline \multirow[t]{2}{*}{ Gender } & \multicolumn{2}{|r|}{ Female } & Total \\
\hline & \multicolumn{2}{|l|}{$57.4 \%$} & $100 \%$ \\
\hline \multicolumn{4}{|c|}{ TABLE III: AGE OF FOCUS GROUP PARTICIPANTS } \\
\hline \multirow[t]{2}{*}{ Age } & $25-44$ & More than 45 & Total \\
\hline & $23 \%$ & $77 \%$ & $100 \%$ \\
\hline
\end{tabular}

$57.4 \%$ of participants were male and $42.6 \%$ of participants were female (see Table II). Their age, in $77 \%$ of cases, exceeded 45 years (see Table III).

The focus groups followed a semi-structured interview guide, which was open and flexible in line with the research method chosen. In particular, after a brief presentation of the project, the focus groups started with the question, "How is working life at the CNR? What is the company climate that you perceive?" Then the groups carried on investigating aspects that, in the eyes of employees, have a central role in their well-being and in the well-being of the organization. The focus groups lasted about 1 hour and 30 minutes.

The study was performed using the Grounded Theory method [20], which consists in constructing a theory by induction from the data collected and not from pre-existing hypotheses. The research is intended to be a circular process with a close and continuous interaction between the data collection and analysis, the formulation of hypotheses and their confirmation in the data.

\section{DATA ANALYSIS}

The focus groups were taped and transcribed. Using qualitative data analysis software NVivo9 [21], interviews transcripts were categorized and coded according to different levels of analysis. Through a process of attribution of meaning to the text based on review of the interview data, categories and dimensions of organizational well-being were identified.

\section{FINDINGS}

Based on the collection and subsequent analysis of coded data, six key areas of organizational well-being in the Agency were identified: tomorrow, staff management, inside and outside, resources, work, participation and accountability. These areas gave rise to 17 dimensions that represent factors that promote or hinder organizational well-being in the CNR: future outlook, innovation, recruitment and staff turnover, staff valuing and professional growth, evaluation, communication and sharing, relationships/integration, sense of belonging, financial and human resources, space, skills, working methods, roles, job satisfaction, decisions, responsibility, risk and prevention. These areas and the respective dimensions are summarized in Fig. 1. In Figs. 2-6 each area has been represented in dimensions and sub-dimensions. In these Figs. the data sources are also specified. Below the contents of each area are described.
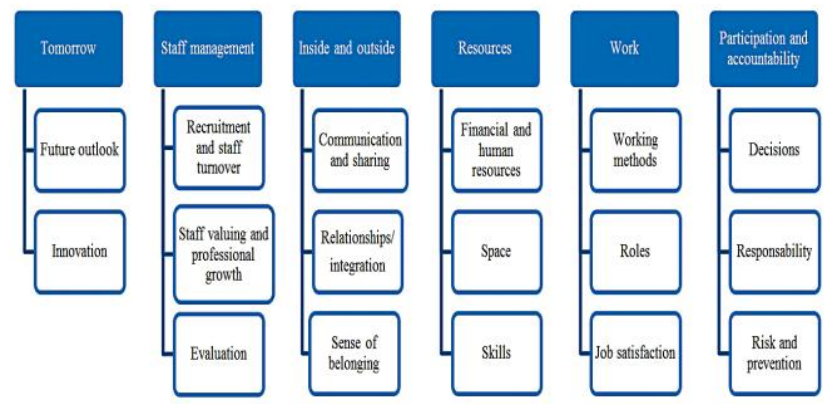

Fig. 1. Areas and dimensions of organizational well-being in the CNR.

\section{A. Tomorrow Area}

This area refers to the CNR's future and to its internal/external changes.

Organizational well-being is supported by a clear and shared vision of the direction that the Agency, throughout a period of time characterized by many changes, will decide to take, also regarding human resources management policies 
(e.g. management policies for temporary workers). Further factors that promote organizational well-being are a non-punitive attitude and a behavior that encourages innovation.

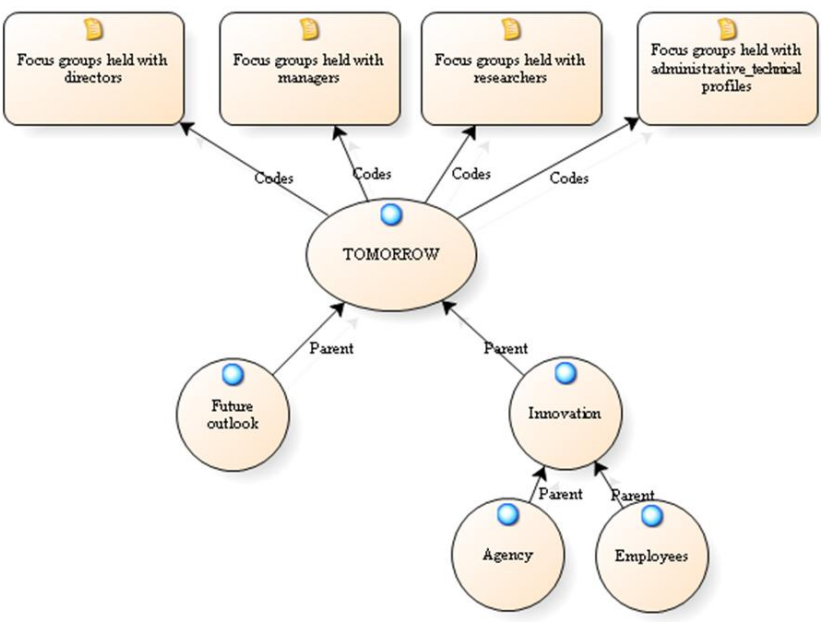

Fig. 2. Tomorrow area.

\section{B. Staff management Area}

This area refers to the way in which human resources are managed, including the recruitment of new staff. It also refers to evaluation based on criteria of transparency and merit, as a possible tool for a better management of human resources.

Organizational well-being is fostered by a good planning of new staff recruitment, taking into account actual needs. Also a low employee turnover of employee and a human resource management that places value on each employee (including people with disabilities) are factors that promote organizational well-being.

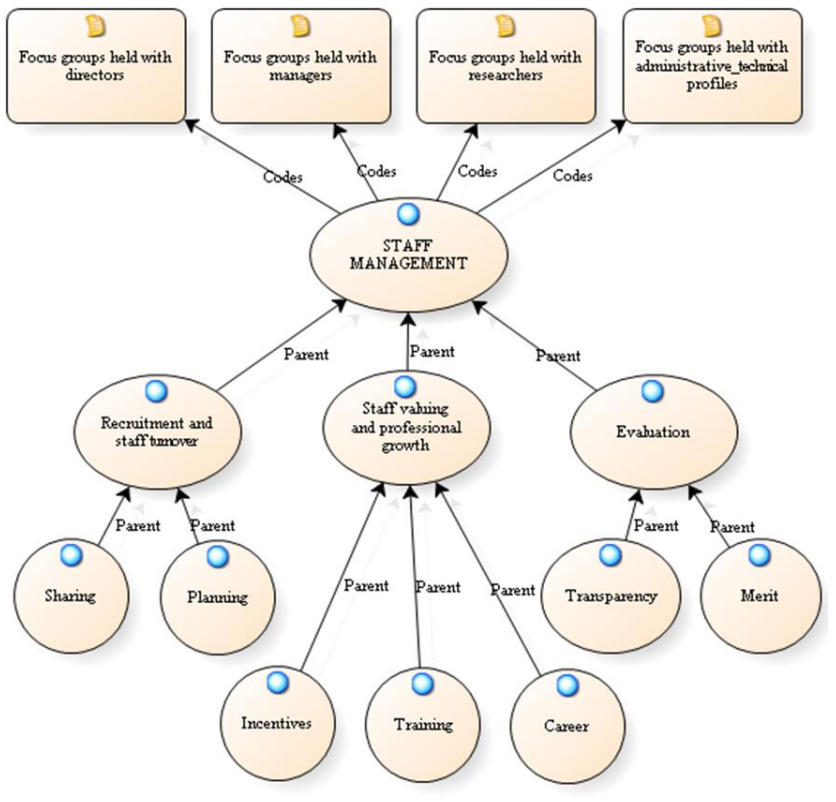

Fig. 3. Staff management area.

\section{Inside and Outside Area}

The inside refers not only to the way in which knowledge and information are managed and social relationships are structured, but also to the sense of belonging. The outside refers to the relationships of the Agency with the outside world.

Organizational well-being is fostered by knowledge and information sharing and also the ability to involve newcomers. Integration between administrative profiles and researchers, the two "cultural souls" of the CNR, and also between research Institutes and Departments, working groups and colleagues (including people with disabilities), are important factors that promote organizational well-being. Integration is also favored by a strong sense of belonging to the organization, which however should not exclude the wider national and international scientific community.

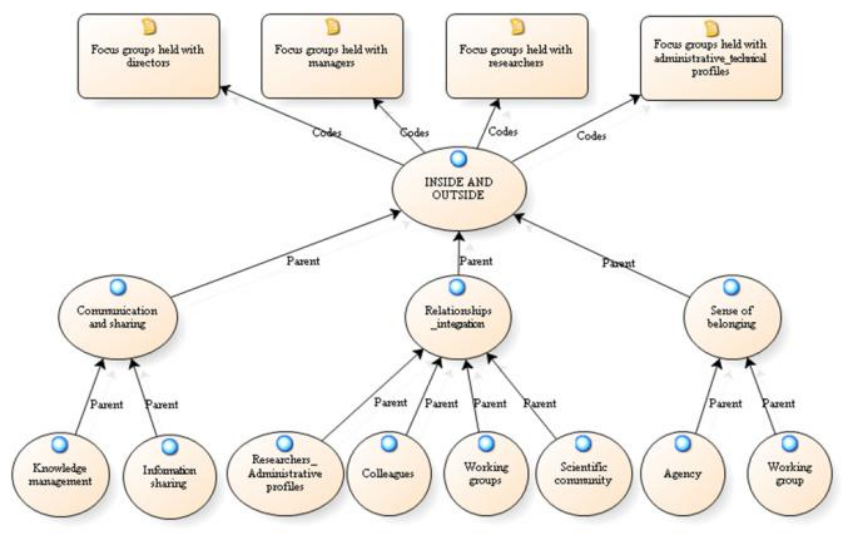

Fig. 4. Inside and outside area

\section{Resources Area}

This area refers to available resources such as staff, money, physical space and expertise, needed to properly carry out work.

Organizational well-being is fostered by the presence of both economic and staff resources. The former is important in order to create incentive programs, such as vocational training opportunities, to perform research without looking for funds outside of the CNR and also to ensure the continuity of employment for young researchers. The latter is important in order to have different competences and roles which allow good work to be carried out. Organizational well-being is also affected by physical space. For example, spaces which are too small and not suited to the number of people seem to adversely influence social relationships.

\section{E. Work Area}

This area refers to working methods, such as time management and workload, but also to leadership ability and job satisfaction.

Organizational well-being is favored by an appropriate distribution of workload and a flexible use of time, but also by a reflexive and well planned working method. A working method that emphasizes teamwork and cooperation rather than individualism contributes to organizational well-being too. Another aspect for the well-functioning of the entire organization is the presence of a leader with coordination and management skills. Also work satisfaction and intrinsic motivation contributes to a state of well-being.

\section{F. Participation and Accountability Area}

This area refers to the way in which decisions are made, responsibilities are assigned and assumed and difficult situations are handled.

Organizational well-being is promoted by participation in decisions, through a bottom-up decision-making process that 
responds to the working needs. The assumption of responsibility according to hierarchical role and position is another aspect which fosters organizational well-being.

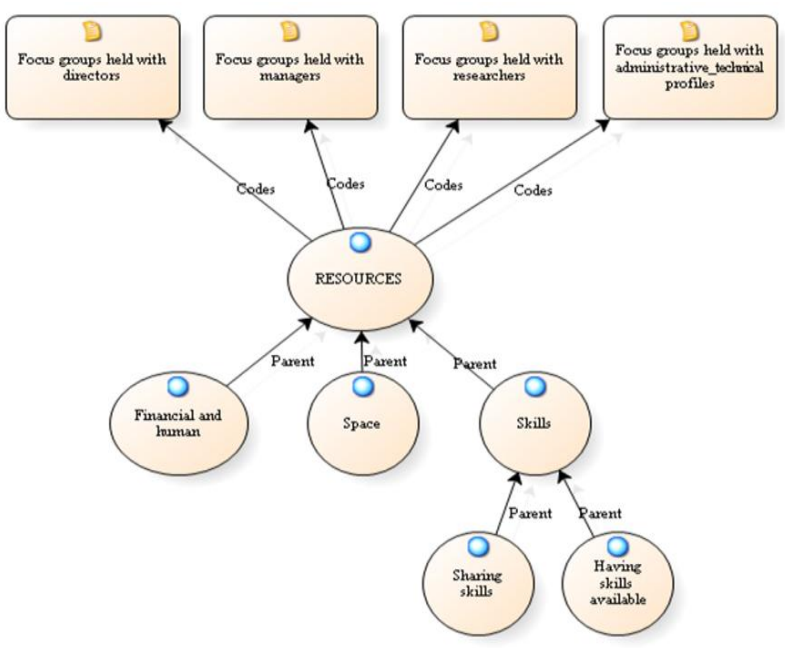

Fig. 5. Resources area.

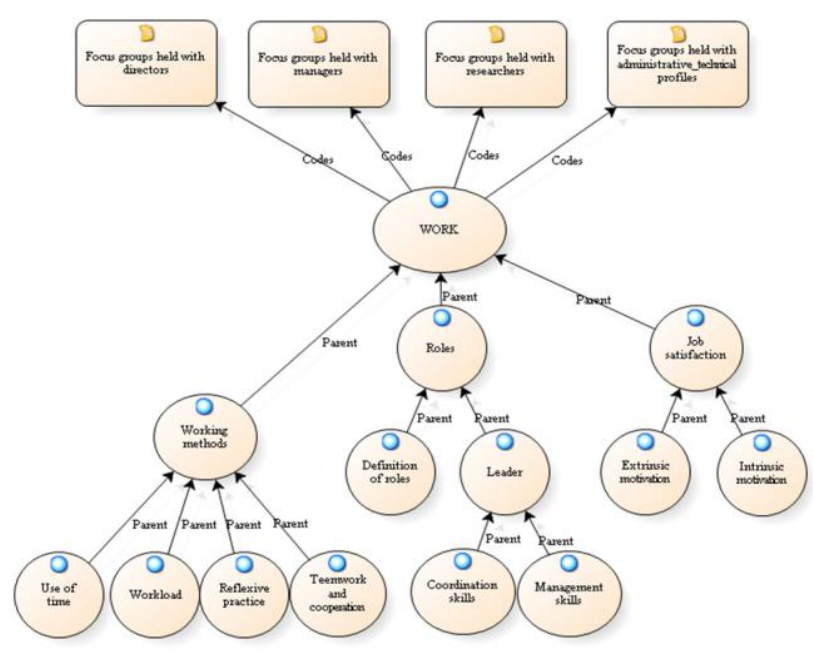

Fig. 6. Work area.

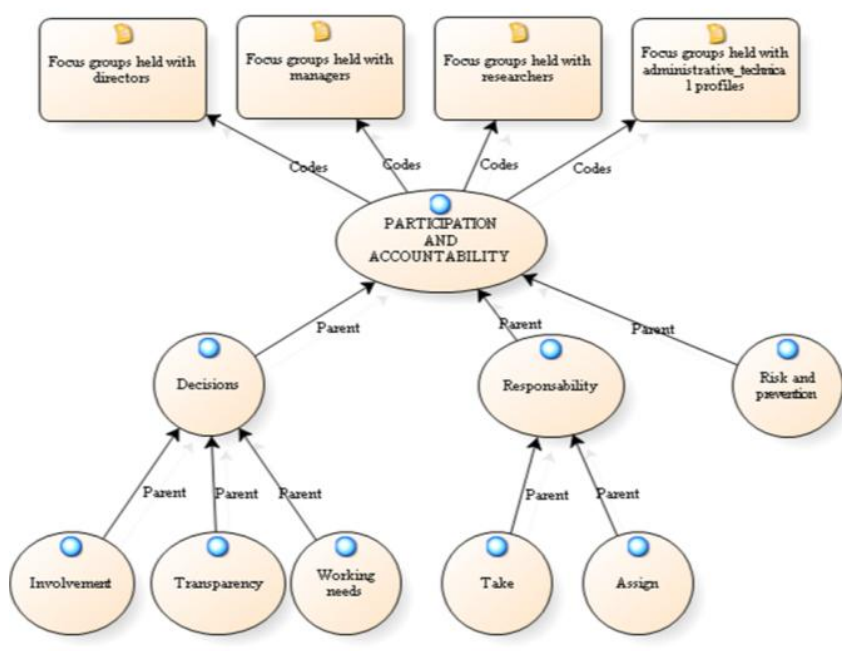

Fig. 7. Participation and accountability area.

\section{DISCUSSION}

The results of this study highlight the value of not only human resources management, but also of knowledge management, relationships (between employees, working groups, the CNR Institutes, the CNR clerks and researchers, the Agency and the national/international scientific context), clarity of the Agency vision, employee future outlook, motivation and participation in decision making as important factors for the organizational well-being of a research agency.

Interventions for organizational health promotion in this or a similar context may be aimed at creating a learning organization model, which is an organization that transmits knowledge, supports learning among its members and promotes information exchange between employees. Additional interventions may be based on the activation of knowledge management processes, which facilitate the explanation of tacit knowledge and a greater knowledge sharing between employees. These processes could also lead to a greater individual and organization responsibility, putting each employee into a position in which they can take part in problem solving. Employee involvement in identifying areas and dimensions of the CNR organizational well-being can also be considered an intervention for organizational health promotion. We are indeed in a context in which decisions tend to be made from the top and employee participation is not often encouraged.

The authors recommend further studies in this area, particularly in knowledge based contexts, such as research agencies and universities, in order to develop a shared model of organizational well-being. For example, the questionnaire planned and carried out to evaluate organizational well-being in the CNR could be validated on a larger sample of research agencies.

\section{REFERENCES}

[1] W. B. Schaufeli, "The future of occupational health psychology," Applied Psychology: An International Review, vol. 53, pp. 502-517, October 2004.

[2] J. E. V. Horn, T. X. Taris, W. B. Schaufeli, and P. J. G. Schreurs, "The structure of occupational well-being: A study among Dutch teachers," Journal of Occupational and Organizational Psychology, vol. 77, pp. 365-375, September 2004.

[3] F. Avallone and A. Paplomatas, Salute Organizzativa, Milano: Raffaello Cortina Editore, 2005.

[4] E. Diener and M. E. P. Seligman, "Beyond money. Toward an economy of wellbeing," Psychological Science in the Public Interest, vol. 5, pp. 1-31, July 2004.

[5] R. H. Rosen, Healthy Companies, New York: Amacom Books, 1986.

[6] I. Donald, P. Taylor, S. Johnson, C. Cooper, C. Cartwright, and S. Robertson, "Work environments, stress and productivity: An examination using ASSET," International Journal of Stress Management, vol. 12, pp. 409-423, November 2005.

[7] P. Warr, "A conceptual framework for the study of work and mental health," Work and Stress, vol. 4, pp. 285-294, 1994.

[8] C. D. Ryff and C. L. M. Keyes, "The structure of psychological well-being revisited," Journal of Personality and Social Psychology, vol. 69, pp. 719- 727, October 1995.

[9] M. G. Wilson, D. M. Dejoy, R. J. Vandenberg, H. A. Richardson, and A. L. McGrath, "Work characteristics and employee health and well-being: Test of a model of healthy work organization," Journal of Occupational and Organizational Psychology, vol. 77, pp. 565-588, December 2004.

[10] K. Danna and R. W. Griffin, "Health and well-being in the workplace: a review and synthesis of the literature," Journal of Management, vol. 25, pp. 357-384, June 1999.

[11] B. A. Juniper, N. White, and P. Bellamy, "A new approach to evaluating the well-being of police," Occupational Medicine, vol. 60, pp. 560-565, October 2010.

[12] D. Guglielmi, A. Paplomatas, S. Simbula, and M. Depolo, "Prevenzione dello stress lavoro correlato: validazione di uno 
strumento per la valutazione dei rischi psicosociali nella scuola," Psicologia Della Salute, vol. 3, pp. 53-74, November 2011.

[13] Presidenza del Consiglio dei Ministri. (February 2013). Alcuni dati. Distribuzione delle amministrazioni per tipologia. Governo italiano [Online]. Available: http://www.magellanopa.it/BenessereOrganizzativo/?qs=Pne84O0rsT qbavdg937WKA.

[14] Gazzetta Ufficiale della Repubblica Italiana (October 2009). Decreto legislativo 27 ottobre 2009 n. 150. Attuazione della legge 4 marzo 2009 n. 15. in materia di ottimizzazione della produttività del lavoro pubblico e di efficienza e trasparenza delle pubbliche amministrazioni. Istituto Poligrafico e Zecca dello Stato [Online]. 197/L. pp. 1-51. Available:

http://www.flcgil.it/files/pdf/20091027/decreto-legislativo-150-del-27 -ottobre-2009-attuazione-della-legge-15-del-4-marzo-2009-4521281.p df.

[15] F. Avallone and M. Bonaretti, Benessere organizzativo. Per migliorare la qualità del lavoro nelle amministrazioni pubbliche, Roma: Rubbettino Editore, 2003.

[16] AA. VV. (March 2011). "Indagine sul benessere organizzativo nel CNR." Consiglio Nazionale delle Ricerche. [Online]. pp. 1-7. Available:

http://www.cnr.it/benessere-organizzativo/docs/Indagine-Benessere-O rganizzativo.pdf.

[17] Consiglio Nazionale delle Ricerche. (February 2013). About CNR. Consiglio Nazionale delle Ricerche. [Online]. Available: http://www.cnr.it/sitocnr/Englishversion/CNR/AboutCNR/AboutCNR .html.

[18] Consiglio Nazionale delle Ricerche. (February 2013). CNR Institutes. Consiglio Nazionale delle Ricerche. [Online]. Available: http://www.cnr.it/istituti/Istituti_eng.html.
[19] Ufficio Programmazione Operativa DCSPI. (November 2011). Risorse umane e finanziarie. Consiglio Nazionale delle Ricerche. [Online] Available:

http://www.cnr.it/sitocnr/IlCNR/Datiestatistiche/Datiestatistiche_file/r isorse_umane_finanziarie.pdf.

[20] A. Strauss and J. Corbin, Basic of Qualitative Research. Grounded Theory Procedures and Techniques, Newbury Park: Sage, 1990.

[21] L. Coppola, NVivo: un programma per l'analisi qualitativa, Milano: Franco Angeli, 2011

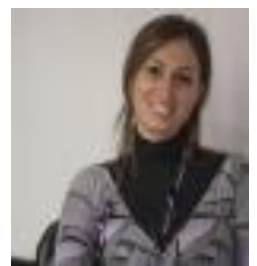

Elisa Colì was born in Galatina, Lecce, in Southern Italy. She earned her degree in Psychology at the University "G. D'Annunzio" in Chieti, Italy, in 2005 and attended postgraduate school specializing in Health Psychology at the University "Sapienza" in Rome, Italy, in 2012. She worked in senior high schools conducting educational workshops aimed at promoting the active citizenship. She has a professional partnership with the University "Uninettuno" for e-learning activities. Furthermore, since 2007, she has been working as junior researcher at the Institute of Cognitive Sciences and Technologies of the Italian National Research Council, in Rome. She attended several National and International Conferences, and published books and articles. Some of her publications include: Quale lavoro? Una ricerca-intervento sull'inserimento lavorativo delle persone con disagio psichico (Roma, Italy: Carocci, 2013); Il benessere, il clima e la cultura delle organizzazioni: significati ed evoluzione in letteratura (Roma, Italy: CNR, 2012); La Valutazione Partecipata de Centri diurni per la Salute Mentale nel Comune di Roma: un'esperienza di ricerca-intervento in contesto sociosanitario (Milano, Italy: Franco Angeli, 2010). Her main research interests are in well-being in working contexts mental health, social and working inclusion of people with disabilities. 